\title{
Modeling of thermal behavior and mass transport in multi-layer laser additive manufacturing of Ni-based alloy on cast iron
}

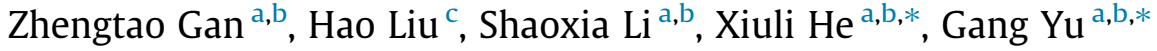 \\ ${ }^{a}$ Key Laboratory of Mechanics in Advanced Manufacturing, Institute of Mechanics, Chinese Academy of Sciences, Beijing 100190, China \\ ${ }^{\mathrm{b}}$ School of Engineering Science, University of Chinese Academy of Sciences, Beijing 100049, China \\ 'School of Mechanical and Electrical Engineering, China University of Mining and Technology, Xuzhou 221116, China
}

\section{A R T I C L E I N F O}

\section{Article history:}

Received 15 January 2017

Received in revised form 11 April 2017

Accepted 11 April 2017

Available online 18 April 2017

\section{Keywords:}

Additive manufacturing

Thermal behavior

Mass transfer

Liquid-gas interface

Solidification

Functionally graded materials

\begin{abstract}
A B S T R A C T
During multi-layer additive manufacturing, multiple thermal cycles and addition of dissimilar-metal powder, even functionally graded materials (FGMs), lead to complicated transport phenomena and solidification behavior in the molten pool, which significantly impact the microstructure evolution and mechanical properties of deposited part. In this study, a predictive three-dimensional numerical model is developed to understand the multi-physical processes such as thermal behavior, Marangoni effect, composition transport, solidification behavior, and dendrite growth in multi-layer additive manufacturing of Ni-based alloy on cast iron. Dimensional analysis is performed to simplify the force balance equation on the liquid-gas interface, which determines the dynamic profile of molten pool. The conservation equations of mass, momentum, enthalpy and concentration are solved in parallel. Transient temperature distribution and thermal cycles at different locations are obtained. The solidification parameters at the liquid-solid interface are evaluated to interpret the solidification microstructure. The distribution of alloy elements and composition profile ( $\mathrm{Ni}$ and $\mathrm{Cr}$ ) are also present and compared with the relevant experimental results. The results show that the cooling rate declines progressively as the subsequent layers deposit, which results in the coarser solidified grains in the upper of part. Even though the powder and substrate can be efficiently mixed to be a homogeneous molten pool, a non-uniform concentration distribution is observed at the bottom of the deposited part, which agrees well with the experimental composition profile using Energy Dispersive Spectrometer (EDS).
\end{abstract}

(c) 2017 Elsevier Ltd. All rights reserved.

\section{Introduction}

Laser powder blown additive manufacturing is an advanced manufacturing process for near-net-shape materials, even functionally graded materials (FGMs), in aviation, aerospace, automobile, and other industries [1,2]. During this process, multi-physical and multi-scale phenomena simultaneously occur and impact the microstructure and mechanical properties of parts. The metallic powder flow interacts with the focused laser beam before depositing on the base metal. A molten pool is rapidly formed on the surface of the substrate. The addition of powder and solidification of molten pool result in the formation of macro-structure along the laser scanning path. Temperature gradient on the surface of molten pool leads to a significant spatial gradient of surface tension, which drives a strong convection of liquid metal (Marangoni flow) and facilitates

\footnotetext{
* Corresponding authors at: Key Laboratory of Mechanics in Advanced Manufacturing, Institute of Mechanics, Chinese Academy of Sciences, Beijing 100190, China.

E-mail addresses: xlhe@imech.ac.cn (X. He), gyu@imech.ac.cn (G. Yu).
}

convective heat and mass transport in the molten pool [3,4]. Multiple thermal cycles due to the bidirectional laser scanning and composition redistribution owing to the addition of dissimilar-metal powder affect the microstructure evolution and mechanical properties of deposited layers $[5,6]$. In order to design the suitable process parameters and regulate the microstructure evolution, composition distribution and mechanical properties of the manufactured part, a thorough understanding of the details of transport phenomena, Marangoni effect, and solidification behavior is crucial [7]. What is required but currently unavailable is a predictive, well-tested, multi-physical process model. It can be utilized as a foundation for understanding the basic physical phenomena and selecting the key process parameters, and forming parts with sound microstructure, non-defect, and excellent performances based on scientific principles.

Because of difficulty in modeling and high computational costs, most current models concentrated on the single-track additive manufacturing process. A transient 3D numerical model was built to obtain the thermal distribution and velocity field within the 
molten pool during additive manufacturing process [8]. In order to simulate the powder addition process, a computationally intensive approach, Level-Set method, was introduced into the numerical model to capture the liquid-gas interface of molten pool [9]. Sets of dimensionless conservation equations were established and solved to examine the molten pool dimensions, temperature distribution and cooling rate in direct laser deposition [10]. Gan et al. proposed a heat transfer and multicomponent mass transfer model to predict the thermal behavior and composition profile in laser additive manufacturing. Some key solidification parameters such as temperature gradient, growth rate and cooling rate were also evaluated based on the temperature field [11].

With the development of Laser Engineered Net Shaping (LENS) and three-dimensional laser repairing, it is very urgent to understand the transport phenomena and solidification behavior in the multi-layer and multi-track process [12,13]. A mathematical model in multi-track laser hardening of AISI 4140 steel was proposed to investigate multiple hardening and overlapping passes [14]. A 3D heat transfer finite element model was used to obtain the molten pool geometry, thermal cycles and hardness distributions in laser additive manufacturing [15]. Numerical simulation of heat transfer and its influence on the scale and morphology of microstructure in electron beam additive manufacturing of IN718 was reported. The columnar to equiaxed transition was examined by using an improved grain growth model [16]. However, in above studies, liquid metal flow within the molten pool was neglected, which has been proven to be the dominative mechanism of heat and mass transfer in the molten pool $[11,17]$.

Few researchers considered the liquid metal flow (Marangoni effect) within the molten pool during the multi-track or multilayer additive manufacturing process [18-20]. A two-dimensional (2D) transport phenomena model in multi-layer additive manufacturing was reported. An arbitrary Lagrangian-Eulerian Method (ALE) was implemented to track the liquid-gas interface of molten pool [18]. A predictive heat transfer and fluid flow model was proposed during the double-track additive manufacturing process. Heat transport, fluid flow, and dynamic surface evolution were included in the simulation [19]. Debroy et al. developed a transient, $3 d$, transport phenomena numerical model for the multi-layer direct laser deposition with coaxial powder feeding [20]. The evolution of experimental solidification texture was also evaluated in comparison with the numerical simulation [5]. Although the additive manufacturing of dissimilar-metal powder (i.e. compositions of the powder are different from that of the substrate) and the FGMs have been used in the fields [21-23], the solidification behavior, mass transfer, element redistribution, and solute segregation have not been thoroughly understood in multi-layer or multi-track additive manufacturing.

In this paper, in order to understand the heat transport, solidification behavior and solute transport in multi-layer additive manufacturing, a 3D, transient, heat and mass transfer, and liquid metal flow numerical model is developed for the laser additive manufacturing of Ni-based alloy on cast iron. The conservation equations of mass, momentum, energy and concentration are solved using a boundary-fitted curvilinear coordinate system to consider the transient changes in the geometry. Temperature distribution and thermal cycles at different locations can be predicted. Based on the computed temperature distribution, the solidification parameters at the liquid-solid interface are evaluated to interpret the evolutional microstructure. Furthermore, the redistribution of alloy elements and composition distribution during the process is present. The computed molten pool geometry and composition profile are compared with the relevant experimental results.

\section{Numerical modeling}

The multi-physical phenomena in the multi-layer additive manufacturing are shown in Fig. 1. The assumptions used in this study are listed $[20,24]$ :

1. The liquid metal flow within the molten pool is laminar, incompressible, and Newtonian.

2. The surface tension is temperature-dependent and composition-independent.

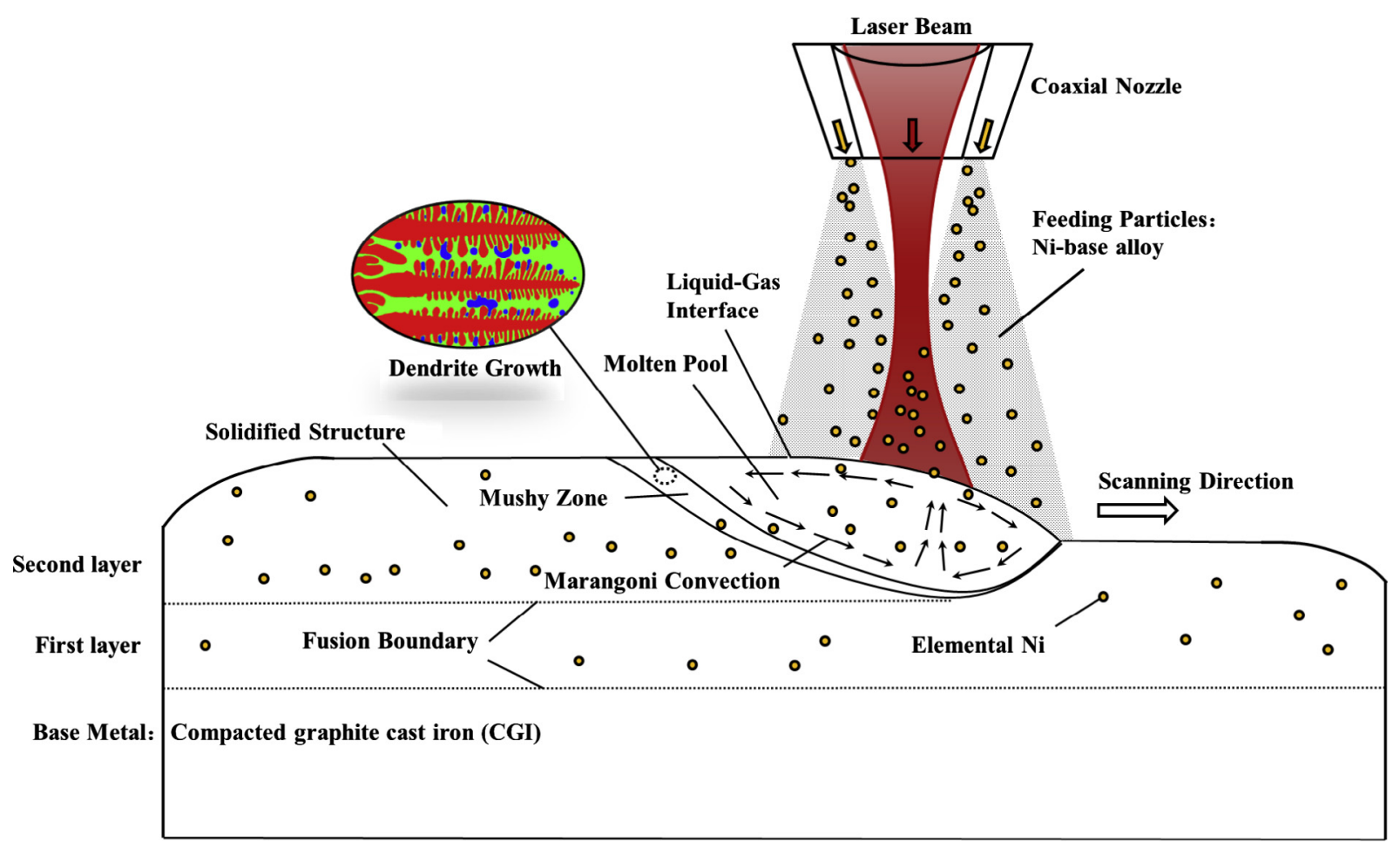

Fig. 1. Multi-physical phenomena in multi-layer additive manufacturing. 
3. The heat flux of laser beam and concentration flux of powder flow is Gaussian.

4. The heat loss due to thermal radiation is ignored in this study.

5. The heat loss and composition loss resulting from the liquid metal vaporization is ignored.

6. The mushy region where the temperature is from solidus to liquidus is an isotropic porous medium.

7. The momentum due to the metallic particle impacting the molten pool is ignored.

8. The diffusion transfer in the solid phase is ignored.

9. A pseudo-binary equivalent is assumed for the multicomponent alloy in solidification modeling.

10. Microsegregation of solutes during the solidification process is disregarded.

\subsection{Conservation equations}

The conservation equations of mass, momentum, heat and concentration in the domain are present in Eqs. (1)-(4) [11,17].

$\frac{\partial \rho}{\partial \mathrm{t}}+\frac{\partial\left(\rho u_{i}\right)}{\partial x_{i}}=0$

$\frac{\partial\left(\rho u_{i}\right)}{\partial \mathrm{t}}+\frac{\partial\left(\rho u_{i} u_{j}\right)}{\partial x_{i}}=\frac{\partial}{\partial x_{i}}\left(\mu \frac{\partial u_{j}}{\partial x_{i}}\right)-\frac{\partial p}{\partial x_{i}}+\frac{\partial}{\partial x_{j}}\left(\mu \frac{\partial u_{j}}{\partial x_{i}}\right)-K_{0} \frac{\left(1-f_{l}\right)^{2}}{f_{l}^{3}+B} u_{i}$

$\frac{\partial\left(\rho c_{p} T\right)}{\partial \mathrm{t}}+\frac{\partial\left(\rho u_{i} c_{p} T\right)}{\partial x_{i}}=\frac{\partial}{\partial x_{i}}\left(k \frac{\partial T}{\partial x_{i}}\right)-\frac{\partial \Delta H}{\partial t}-\frac{\partial\left(\rho u_{i} \Delta H\right)}{\partial x_{i}}$

$$
\begin{aligned}
& \frac{\partial(\rho C)}{\partial \mathrm{t}}+\frac{\partial\left(\rho u_{i} C\right)}{\partial x_{i}}=\frac{\partial}{\partial x_{i}}\left(\rho D \frac{\partial C}{\partial x_{i}}\right)+\frac{\partial}{\partial x_{i}}\left(\rho D \frac{\partial\left(C_{l}-C\right)}{\partial x_{i}}\right) \\
& -\frac{\partial}{\partial x_{i}}\left(\rho f_{s}\left(C_{l}-C_{s}\right) u_{i}\right)
\end{aligned}
$$

where $t$ represents the time, $u_{j}$ is the $j$ th component of velocity, $\mu$ represents the viscosity, $p$ is pressure, and $T$ is the temperature, $c_{p}$ denotes the specific heat, $\rho$ is the density, $k$ is the thermal conductivity, $C$ and $D$ represent the concentration and the diffusion coefficient of element. The fourth term on the right side of Eq. (2) formulizes the frictional dissipation in the mushy region [25]. The mass transfer is simulated based on Eq. (4). The second and third terms on the right side of Eq. (4) are the solute partitioning at the solid-liquid interface [26]. $\Delta H$ represents the latent enthalpy content of the fusion. The detailed of conservation equations have been reported in our previous study [11,17].

In order to fit the curved surface profile of molten pool, a nonorthogonal deformable grid is implemented in this study. The above conservation equations are transformed from the Cartesian to the curvilinear coordinate system based on the theory of coordinate transformation [27]. The detailed deducing of coordination transformation and transformed conservation equations are available in the published literatures [28].

\subsection{Boundary conditions}

The Gaussian heat flux of laser beam at the liquid-gas interface is defined as,

$q_{\text {ener }}=\frac{2 Q\left(1-\eta_{p}\right) \eta_{l}}{\pi r_{b}^{2}} \exp \left(\frac{-2\left(\left(x-V_{s} t\right)^{2}+y^{2}\right)}{r_{b}^{2}}\right)-h_{c}\left(T-T_{0}\right)$

where $Q$ represents the laser power, $\eta_{p}$ represents the fraction of the laser energy absorbed by the in-flight powder, $\eta_{l}$ represents the fraction of the laser energy absorbed by the base metal, $r_{b}$ rep- resents the radius of the laser beam, $V_{s}$ represents the scanning speed of laser, $h_{c}$ represents the heat transfer coefficient, $T_{0}$ represents the ambient temperature. $\eta_{l}$ is a crucial coefficient that depends on both of material and temperature. Hagen-Rubens relationship is a plausible estimation of the near-infrared laser absorptivity [29]. $\eta_{l}(T)$ is estimated from the temperature-dependent electrical resistivity of the material $R_{e}(T)$ by the following formula,

$\eta_{l}(T)=\left(8 \varepsilon_{0} \omega R_{e}(T)\right)^{1 / 2}$

where $\omega$ represents the angular frequency of the near-infrared laser and $\varepsilon_{0}$ is the permittivity of free space. The temperature-dependent resistivity $R_{e}(T)(\mu \Omega / \mathrm{m})$ for liquid Ni-based alloy is empirically formulated as [30],

$R_{e}(T)=1.251+1.346 \times 10^{-4} T$

The powders are interacted with the laser beam after being ejected from the nozzle. The absorbed heat by in-flight powder depends on the powder size, velocity of the gas, powder properties, laser energy density, and residence time. The laser energy absorbed by laser-powder interaction is expressed as a source term in the energy equation:

$S_{\text {ener }}=\frac{2 Q \eta_{p}}{\pi r_{b}^{2} d} \exp \left(\frac{-2\left(\left(x-V_{s} t\right)^{2}+y^{2}\right)}{r_{b}^{2}}\right)$

where $d$ represents the depth of the molten pool, which is determined iteratively. The corresponding boundary conditions for the momentum equations at the liquid-gas interface, including the surface tension and thermocapillary force, can be defined as [18],

$F_{L / G}=\sigma \boldsymbol{n} \kappa-\nabla_{s} T \frac{d \sigma}{d T}$

where $\sigma$ represents the surface tension of liquid metal, $\boldsymbol{n}$ is the normal of surface, $\kappa$ represents the curvature of surface.

The corresponding boundary conditions for concentration equations at the liquid-gas interface are formulated as follow [11],

$q_{i}=\chi_{i} \frac{2 m_{f} \eta_{m}}{M_{i} \pi r_{p}^{2}} \exp \left(\frac{-2\left(\left(x-V_{s} t\right)^{2}+y^{2}\right)}{r_{p}^{2}}\right)$

where $q_{i}$ is the concentration flux of the $i$ th component of powder, $m_{f}$ represents the powder flow rate, $\eta_{m}$ represents the powder catchment efficiency, $r_{p}$ represents the radius of powder flow. $\chi_{i}$ represents the molar fraction of the $i$ th component of powder and $M_{i}$ represents the molar mass of the $i$ th component of powder.

\subsection{Liquid-gas interface profile of molten pool}

Due to the addition of powder, the liquid-gas interface of molten pool becomes a curved surface. Assuming the flat surface of molten pool will lead to the overestimation of thermal behavior and mass transfer [31]. In order to describe the dynamic surface of molten pool, surface tracking [18] or surface capturing methods $[3,9]$ are highly computationally intensive. Dimensional Analysis method [32] is utilized to obtain a simplified equation for the surface profile of molten pool. At quasi-steady-state, the profile of liquid-gas interface of molten pool is derived from the force balance acting on the liquid-gas interface [10],

$\frac{\sigma}{R}+2 \mu \frac{\partial \boldsymbol{v}}{\partial n} \cdot \boldsymbol{n}=p-p_{\infty}+\rho g\left(H_{c}+z_{\text {top }}-z\right)$

where $\sigma$ represents the surface tension, $\boldsymbol{n}$ represents the normal of surface pointing inward to liquid phase, $R$ represents the radius of curvature, $\boldsymbol{v}$ represents the vector of velocity, $p_{\infty}$ represents the ambient pressure, $H_{c}$ represents the built-up height. For estimating 
the magnitude of each term in Eq. (11), some dimensionless parameters can be defined as below [32].

$U_{0}=\frac{\alpha_{0}}{r_{b}}, \quad \boldsymbol{v}^{*}=\frac{\boldsymbol{v}}{U_{0}}, \quad \boldsymbol{r}^{*}=\frac{\boldsymbol{r}}{r_{b}}, \quad \mu^{*}=\frac{\mu}{\mu_{0}}$,

$p^{*}=\frac{p}{\rho_{0} U_{0}^{2}}, \quad \rho^{*}=\frac{\rho}{\rho_{0}}, \quad H_{c}^{*}=\frac{H_{c}}{r_{b}}$,

$\mathrm{Ca}=\frac{\mu_{0} U_{\sigma}}{\sigma}, \quad W e=\frac{\rho_{0} U_{\sigma}^{2} r_{b}}{\sigma}, \quad B o=\frac{\rho_{0} g r_{b}^{2}}{\sigma}$,

$U_{\sigma}=\frac{d \sigma}{d T} \frac{h_{l}-h_{\infty}}{c_{p 0} \mu_{0}}$

where the radius of laser beam, $r_{b}$, is selected as characteristic length, $U_{0}$ is the speed of heat diffusion, which can be selected as the scale of velocity. $h$ is the specific sensible enthalpy. The subscripts 0 and $\infty$ denote the reference and ambient condition, respectively. The Capillary number $(\mathrm{Ca})$, Weber number $(\mathrm{We})$ and Bond number $(B o)$ are defined. $U_{\sigma}$ is selected for estimating the fluid inertia within the molten pool [10].

The shape equation for the liquid-gas interface is nondimensionalized as,

$\frac{1}{R^{*}}+C a 2 \mu^{*} \frac{\partial \boldsymbol{v}^{*}}{\partial n^{*}} \cdot \boldsymbol{n}=W e\left(p^{*}-p_{\infty}^{*}\right)+B o\left(H_{c}^{*}+z_{\text {top }}^{*}-z^{*}\right)$

Based on the previous calculation results [11], the order of magnitudes of $\mathrm{Ca}$, We, and $\mathrm{Bo}$ are $10^{-1}, 10^{4}$ and $10^{-2}$, respectively. It implies that velocity and gravitational terms could be ignored in comparison with the surface tension and differential pressure terms. Thus, in this study, the effect of convection within the molten pool on the free surface profile is neglected. The liquid-gas interface profile of molten pool is calculated by minimizing the total energy of the surface. The total energy of surface involves the surface energy due to the surface curvature and the differential pressure due to impact of the metallic powder. The total energy is therefore given by the following equation [33]:

$E=\iint_{s}\left[\sigma \sqrt{1+\left(\frac{\partial \phi}{\partial \mathrm{x}}\right)^{2}+\left(\frac{\partial \phi}{\partial \mathrm{y}}\right)^{2}}+\frac{1}{2} \rho g \phi^{2}-P_{d} \phi\right] d x d y$

where $s$ denotes the top surface of the computational domain, the variable $\phi$ is the configuration function of the molten pool surface that represents the elevation or depression across a datum level (initial surface of substrate). $P_{d}$ means the pressure owing to the injection of metallic powder, which is assumed to be zero in this study. Detailed procedure for minimizing of the total surface energy, Eq. (13), is available in published literatures [33]. Eqs. (14) and (15) can be solved for obtaining the surface profile of molten pool,

$$
\begin{aligned}
& \sigma\left[\frac{\left(1+\left(\frac{\partial \phi}{\partial \mathrm{y}}\right)^{2}\right) \frac{\partial^{2} \phi}{\partial x^{2}}-2 \frac{\partial \phi}{\partial \mathrm{x}} \frac{\partial \phi}{\partial \mathrm{y}} \frac{\partial^{2} \phi}{\partial x y}+\left(1+\left(\frac{\partial \phi}{\partial \mathrm{x}}\right)^{2}\right) \frac{\partial^{2} \phi}{\partial y^{2}}}{\left(1+\left(\frac{\partial \phi}{\partial \mathrm{x}}\right)^{2}+\left(\frac{\partial \phi}{\partial \mathrm{y}}\right)^{2}\right)^{3 / 2}}\right] \\
& \quad=\rho g \phi+P_{d}+\lambda \\
& \iint\left(\phi_{s}-z_{0}\right) d x d y-t \cdot \iint\left[\frac{2 m_{f} \eta_{m}}{\rho_{m} \pi r_{p}^{2}} \exp \left(\frac{-2\left(x^{2}+y^{2}\right)}{r_{p}^{2}}\right)\right] d x d y=0
\end{aligned}
$$

where $\lambda$ denotes the Lagrange multiplier. Eq. (14) formulizes the force balance equation at any time, and Eq. (15) denotes the corresponding constraint equation that the deposited volume is equal to the amount of powder fed into the molten pool zone. Subscript $m p$ means the molten pool zone, $z_{0}$ represents the initial $z$ location of the substrate top surface, $\rho_{m}$ is the density of powder.

\subsection{Numerical solutions}

A six-layer additive manufacturing process of $\mathrm{Ni}$-based alloy on compacted graphite cast iron (CGI) was numerically simulated. Fig. 2 shows the schematic of the six-layer additive manufacturing process. The view of $\mathrm{x}-\mathrm{z}$ plane is shown. The scanning path is present in the figure. $22 \mathrm{~mm} \times 10 \mathrm{~mm} \times 10 \mathrm{~mm}$ computational domain was built, and a grid system of $290 \times 32 \times 40$ was discretized. Minimum size of the grid is $50 \mu \mathrm{m}$. (The diameter of laser beam is $2 \mathrm{~mm}$.) Half of work piece is taken into account for simplification. The total simulation time in this study is $18,000 \mathrm{~ms}$ and the time step is $0.1 \mathrm{~ms}$. The Courant number can be limited to 2 or less. In each time step, the continuity, momentum, energy and concentration equations are solved. Then, the surface profile of molten pool can be obtained based on the temperature field and input parameters. Based on the surface profile, the $z$ coordinate of grids are varied to fit the change of geometry. And the conservation equations are recomputed in the fitted grid structure. The solution process is repeated until the residuals satisfy the convergence criterion. In order to speed up the calculation, the solver was

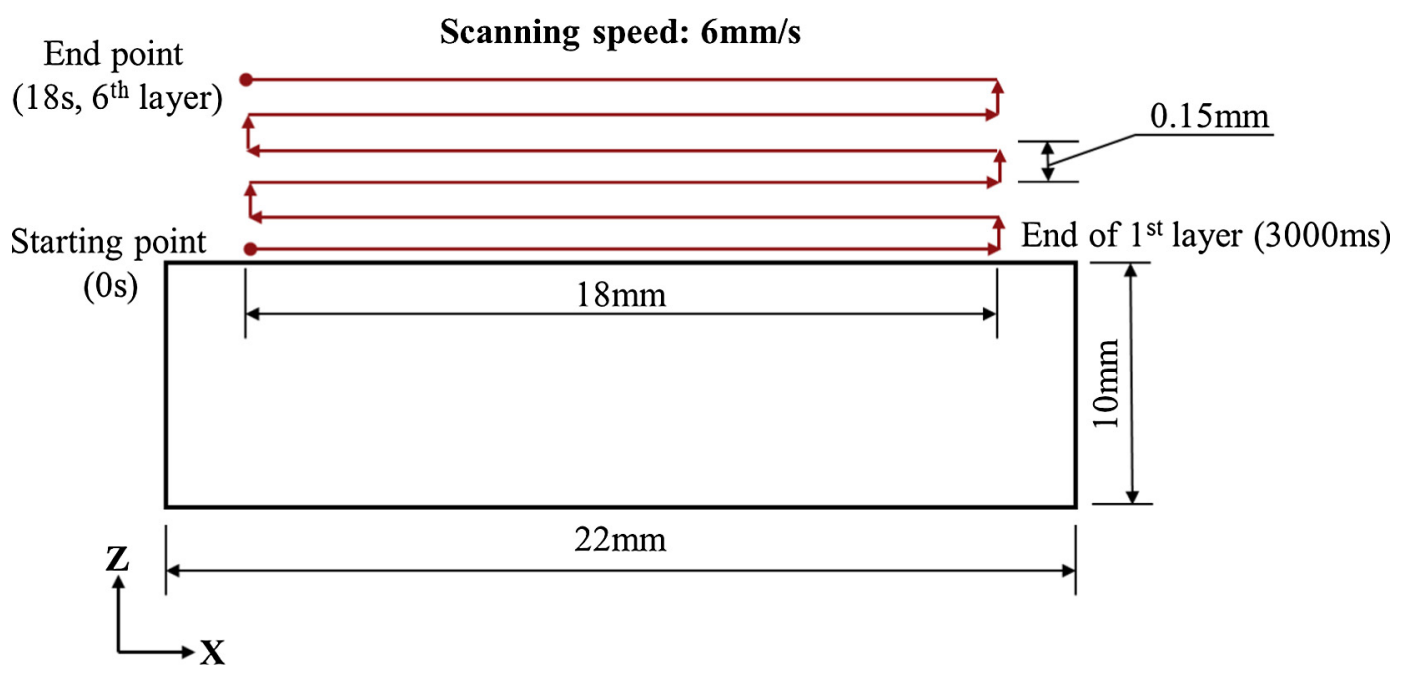

Fig. 2. Schematic of the six-layer additive manufacturing process. 
Table 1

Material compositions of compacted graphite cast iron and Ni-based alloy powder (wt\%).

\begin{tabular}{|c|c|c|c|c|c|c|c|}
\hline & $\mathrm{Fe}$ & C & $\mathrm{Ni}$ & $\mathrm{Al}$ & $\mathrm{Cr}$ & Co & $S$ \\
\hline Cast iron & Bal & 3.6 & - & - & - & - & 0.02 \\
\hline Ni-based alloy & - & - & Bal & 3.4 & 31 & 2.6 & - \\
\hline
\end{tabular}

Table 2

Thermophysical properties of the substrate and powder [6,34].

\begin{tabular}{lll}
\hline Property & $\begin{array}{l}\text { Substrate } \\
\text { (Cast iron) }\end{array}$ & $\begin{array}{l}\text { Powder } \\
(\mathrm{NiCoCr})\end{array}$ \\
\hline Solid density $\rho_{\mathrm{s}}\left(\mathrm{kg} \mathrm{m}^{-3}\right)$ & 7090 & 7500 \\
Liquid density $\rho_{l}\left(\mathrm{~kg} \mathrm{~m}^{-3}\right)$ & 7090 & 6100 \\
Solidus temperature $T_{s}(\mathrm{~K})$ & 1393 & 1616 \\
Liquidus temperature $T_{l}(\mathrm{~K})$ & 1498 & 1650 \\
Solid specific heat $c p_{s}\left(\mathrm{~J} \mathrm{~kg}^{-1} \mathrm{~K}^{-1}\right)$ & 441 & 665 \\
Liquid specific heat $c p_{l}\left(\mathrm{~J} \mathrm{~kg}^{-1} \mathrm{~K}^{-1}\right)$ & 704 & 673 \\
Solid thermal conductivity $k_{\mathrm{s}}\left(\mathrm{W} \mathrm{m}^{-1} \mathrm{~K}^{-1}\right)$ & 43 & 33 \\
Liquid thermal conductivity $k_{l}\left(\mathrm{~W} \mathrm{~m}^{-1} \mathrm{~K}^{-1}\right)$ & 32 & 46 \\
Latent heat of fusion $L\left(\mathrm{~kJ} \mathrm{~kg} \mathrm{~K}^{-1}\right)$ & 8.7 & 10 \\
Dynamic viscosity $\mu($ Pa s) & $5.5 \times 10^{-3}$ & $5.1 \times 10^{-3}$ \\
Temperature coefficient of surface tension $d \sigma /$ & $-4.3 \times 10^{-4}$ & $-3.7 \times 10^{-4}$ \\
$\quad d T(\mathrm{~N}$ m \\
\end{tabular}

Table 3

Calculation data used in the simulation [4,9].

\begin{tabular}{ll}
\hline Parameter & Value \\
\hline Laser power $Q(\mathrm{~W})$ & 900 \\
Beam radius $r_{b}(\mathrm{~mm})$ & 1 \\
Scanning speed $V_{s}(\mathrm{~mm} / \mathrm{s})$ & 6 \\
Mass flow rate $m_{f}(\mathrm{~g} / \mathrm{min})$ & 4.3 \\
Mass flow radius $r_{p}(\mathrm{~mm})$ & 2 \\
Powder catchment efficiency $\eta_{m}$ & 0.9 \\
Absorption coefficient in in-flight powder $\eta_{p}$ & 0.3 \\
Convective heat transfer coefficient $h_{c}\left(\mathrm{~W} \mathrm{~m}^{-2} \mathrm{~K}^{-1}\right)$ & 100 \\
Angular frequency of the laser $\omega\left(\mathrm{rad} \mathrm{s}^{-1}\right)$ & $1.75 \times 10^{15}$ \\
Permittivity $\varepsilon_{0}\left(\mathrm{~F} \mathrm{~m} \mathrm{~m}^{-1}\right)$ & $8.85 \times 10^{-12}$ \\
Ambient temperature $T_{0}(\mathrm{~K})$ & 293 \\
Solute partition coefficient $k_{p}$ & 1 \\
\hline
\end{tabular}

parallelized using OPENMP tools in a computing platform with $12 \times 2.5 \mathrm{GHz}$ CPU and $24 \mathrm{~GB}$ memory. The total time of actual computation is about $30 \mathrm{~h}$. Table 1 presents the compositions of powder and base metal. Table 2 shows the thermophysical properties of materials. Table 3 shows the calculation data used in this simulation.

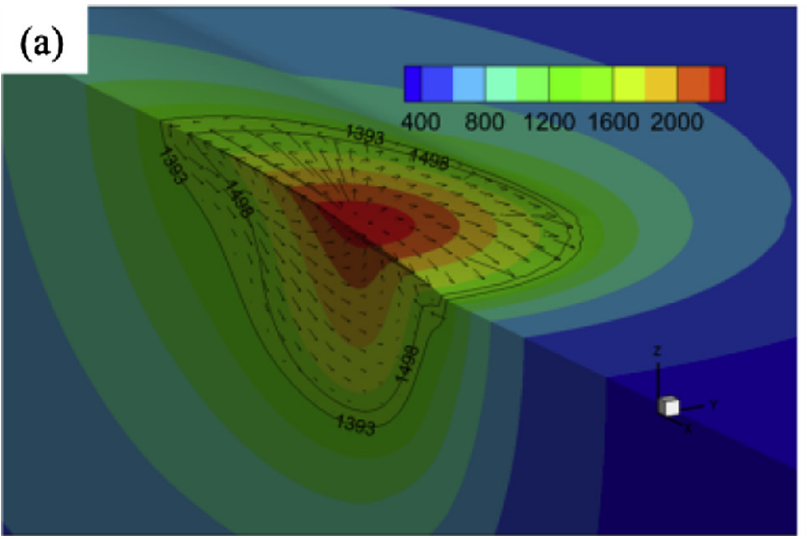

\section{Results and discussions}

\subsection{Thermal behavior}

\subsubsection{Heat conduction and convection}

Fig. 3 shows the computed temperature field and velocity field within the molten pool at the time of $1500 \mathrm{~ms}$ (i.e. at the midlength of first layer). In Fig. 3(a), the temperature field is shown by the contour. The velocity in the molten pool is indicated by the black arrows. The liquidus and solidus are present by the black isotherms. In Fig. 3(b), the contour indicates the velocity magnitude. A reference vector of $1 \mathrm{~m} / \mathrm{s}$ is shown in the figure. The relative importance of conduction and convection in the molten pool is evaluated by Peclet number [32],

$P e_{T}=\frac{u L_{R}}{\alpha_{h}}$

where $u$ represents the characteristic velocity ( $1 \mathrm{~m} / \mathrm{s}$ in this case), $L_{R}$ represents the characteristic length (laser beam radius, $10^{-3} \mathrm{~m}$, in this case), $\alpha_{h}$ represents the thermal diffusivity $\left(10^{-5} \mathrm{~m}^{2} / \mathrm{s}\right.$ in this case). Thus, the $P e_{T}$ is on the order of $10^{2}$, which means the heat transfer in the molten pool is dominated by convection (liquid metal flow). Because of the negative temperature coefficient of surface tension $\left(-3.7 \times 10^{-4}\right.$ in this case), the fluid flow is outward from the center to the periphery of molten pool, resulting in convective heat transfer in the molten pool.

\subsubsection{Thermal cycles}

Fig. 4(a)-(f) shows the evolution of computed temperature field and built-up geometry during the 1st-6th layer. As expected, the region with the highest laser density has the highest temperature. The maximum temperature in the domain of the molten pool at different time is present in Fig. 5. As shown in Fig. 5, in the initial stage of process, due to the high-density of laser heat flux, the temperature rapidly increases. After about $15 \mathrm{~ms}$, the maximum temperature is more than the solidus and the formation of molten pool begins. After about $900 \mathrm{~ms}$, the peak temperature of molten pool is relatively steady $(2350 \mathrm{~K})$ until the end of the first layer process. At the time of $3000 \mathrm{~ms}$, the scanning of the first layer completes, and the reverse scanning begins. As shown in Fig. 5, the maximum tem-

Fig. 3. Computed temperature and velocity distribution at $1500 \mathrm{~ms}$ (at the mid-length of first layer): (a) temperature field, (b) velocity field. 

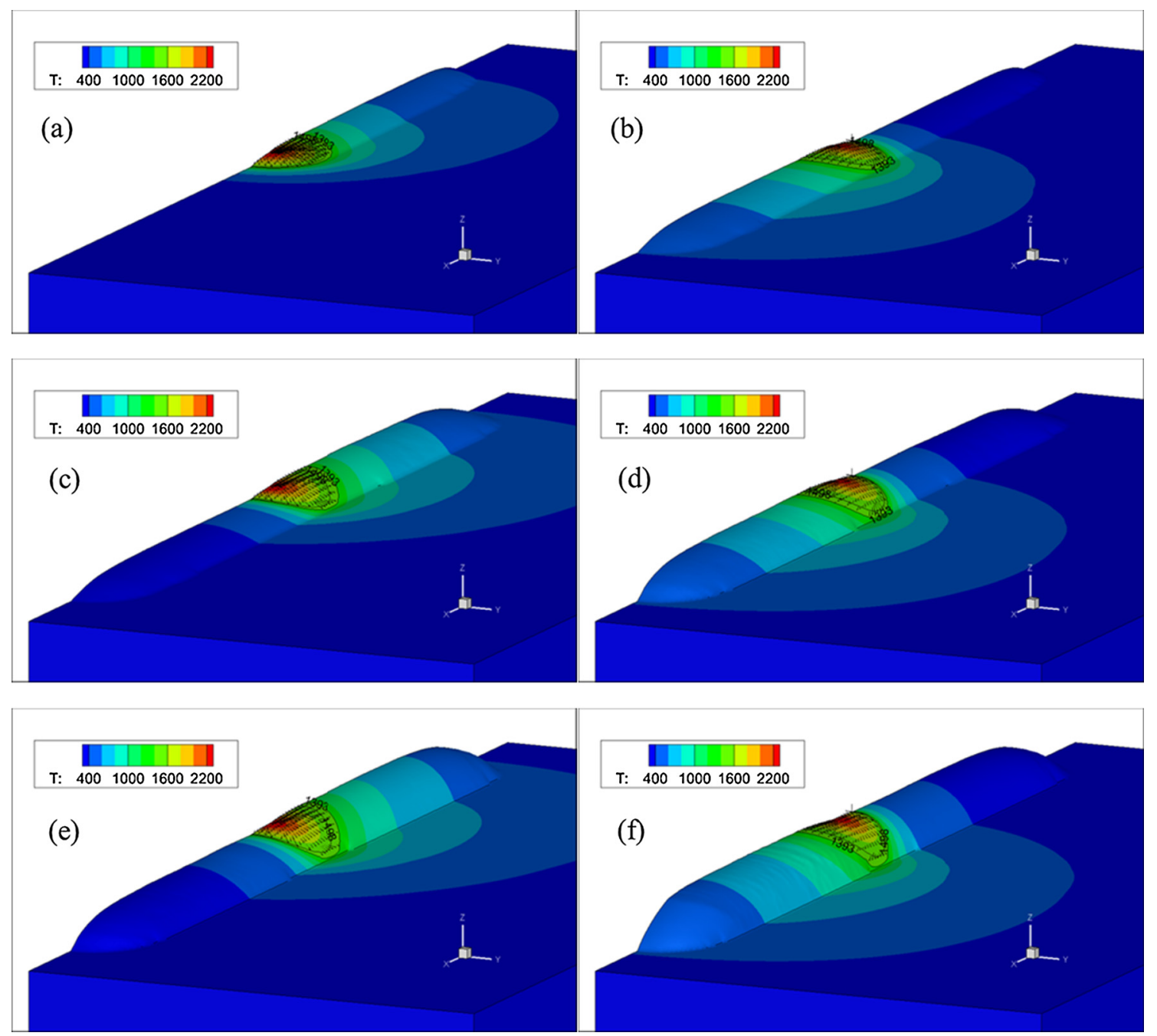

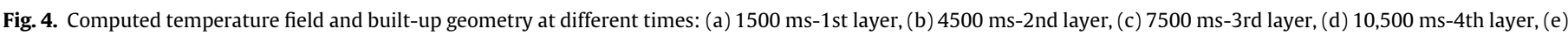
$13,500 \mathrm{~ms}-5$ th layer, and (f) $16,500 \mathrm{~ms}-6$ th layer.

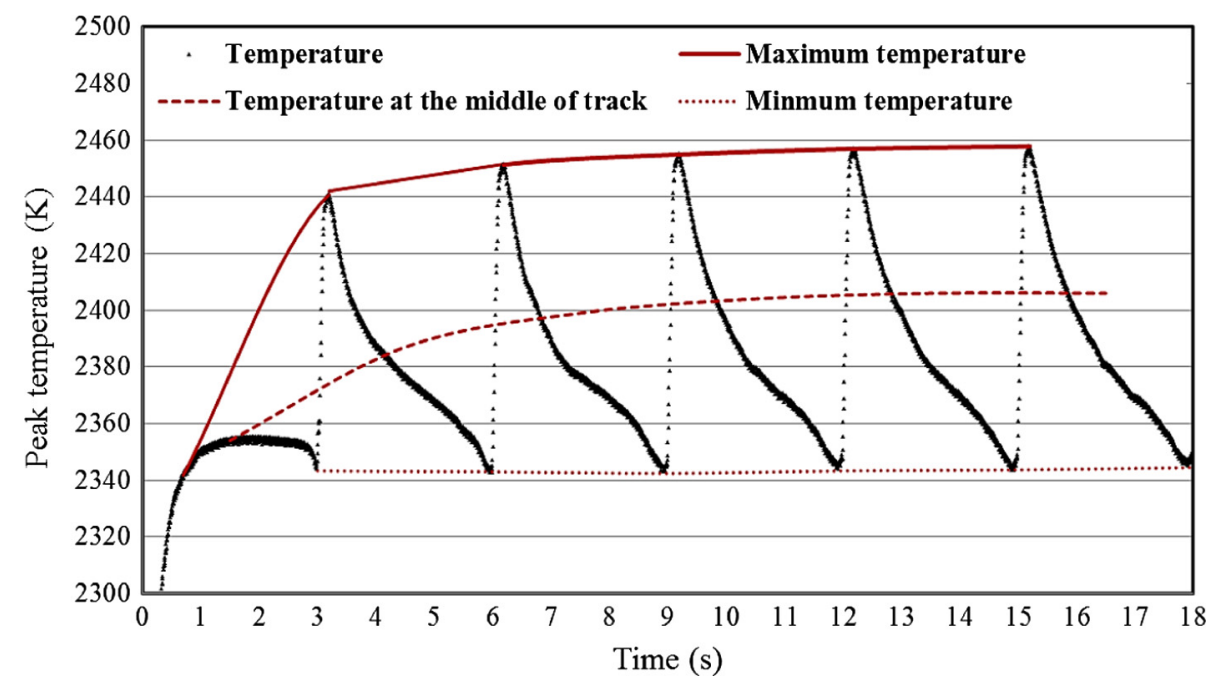

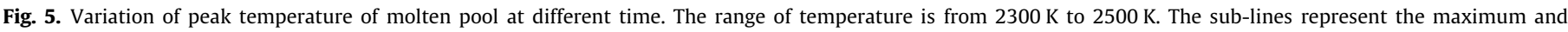
minimum temperature at each layer and temperature at the mid-length of track, respectively.

perature rapidly increases from $2350 \mathrm{~K}$ to $2440 \mathrm{~K}$ at $3000 \mathrm{~ms}$, because of the insufficient heat transfer at this position. Then the peak temperature gradually decreases until the end of the track.
The peak temperature in the 1st layer is obviously lower than that in other layers. Because the temperature of the base metal is ambient temperature initially, the heat flux into the base metal is high 
at first layer. As the deposition of the subsequent layers, owing to the increase of temperature of base metal, the peak temperature increases. However, the temperature rise slows down as the deposition process continues, because the higher temperature leads to higher heat loss caused by natural convection.

The calculated thermal cycles at mid-length and top surface within the first, third, and fifth layers are shown in Fig. 6. Each thermal cycle presents the rapid melting and solidification processes and the progress of deposition processes. From the plot of thermal cycles, the rate of melting and cooling can be obtained to interpret the real solidification behavior of molten pool, which will be discussed in the next section. The calculated peak temperatures in each layer are shown in Fig. 7. The peak temperature raises in the upper layers due to the multiple laser energy inputs and diminished heat transfer into the base metal. In comparison with the calculated peak temperature with present model, the computed result without considering fluid flow is also shown in Fig. 7. As expected, because the convective heat transfer is neglected in the molten pool, the computed peak temperature is overestimated with the heat conduction model, which results in quick rise in peak temperature. Thus, some conclusions only made by the heat conduction simulations may be revised.

\subsubsection{Solidification behavior}

The cross-sections of the calculated geometry of molten pool in different layer are present in Fig. 8(a)-(c). The experimental crosssections are also present in the figure. As shown in Fig. 8, the calculated geometries agree well with the relevant experimentally observed result, which indicates that the present model has abilities to predict the accuracy dimensions of the deposited layers.

Solidification of the molten pool is remarkably influence by the thermal behavior. Two key parameters impact the formation of microstructure at the liquid-solid interface, temperature gradient $(G)$ and growth rate $(R)$. $G$ represents the temperature gradient normal to the liquid-solid front and $R$ represents the velocity of the liquid-solid front as follow,

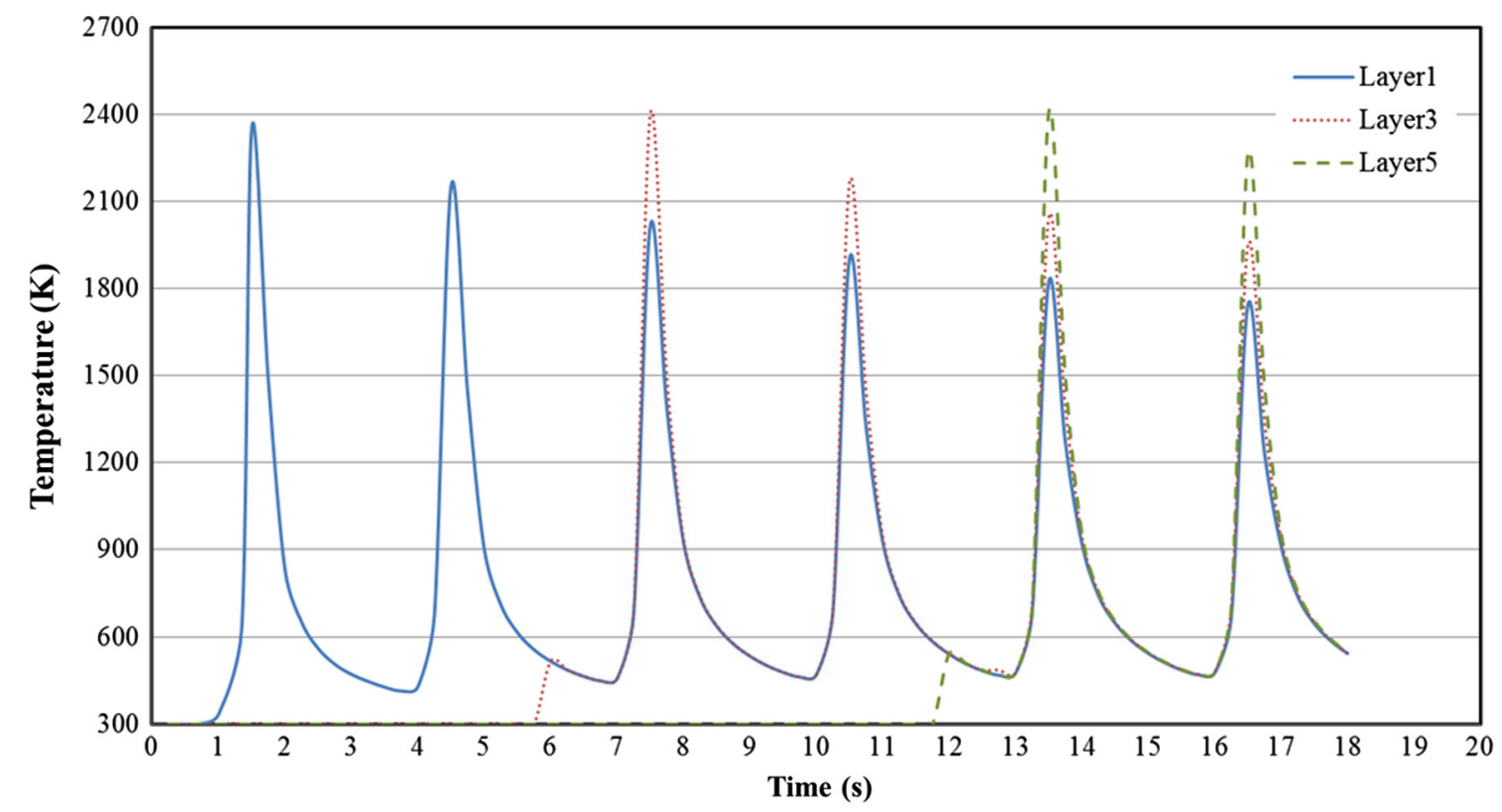

Fig. 6. Thermal cycles at three monitoring locations in 1st layer, 3rd layer and 5th layer.

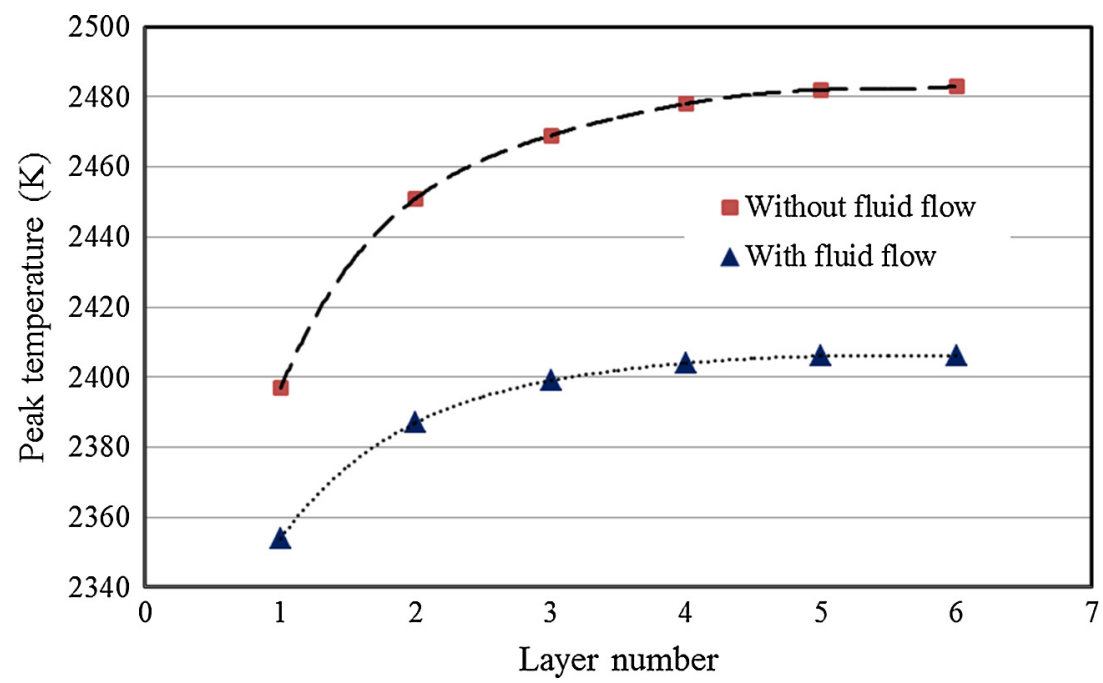

Fig. 7. Peak temperature of molten pool at different layer with the present model and a conduction model, in which the fluid flow is neglected. 

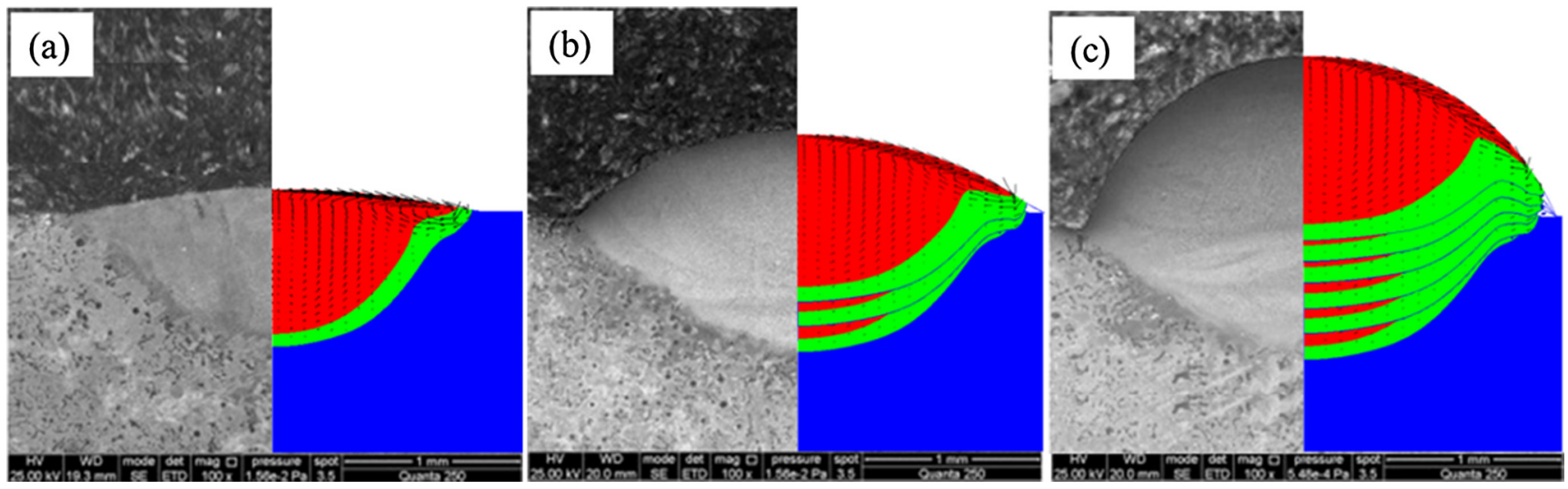

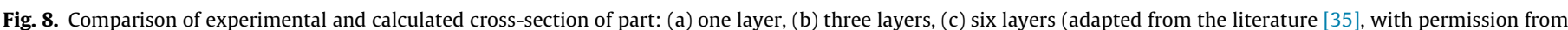
Elsevier).

$G=\nabla T \cdot \boldsymbol{n}$

$R=V s \cdot \boldsymbol{i} \cdot \boldsymbol{n}$

where $\boldsymbol{n}$ represents the unit normal vector of the liquidus and $\boldsymbol{i}$ represents the unit vector of scanning direction. The cooling rate is defined as $G \times R$, which affects the scale of microstructure [36]. Lower cooling rate leads to coarser size of grain. The morphology factor is defined as $G / R$, and the morphology of solidified microstructure changes from dendritic, cellular to planar as the $G /$ $R$ increases [36].

Fig. 9 shows the variation of temperature gradient $G$ and growth rate $R$ as a function of layer depth along the symmetry plane at the mid-length of the first layer. The molten pool shape on the symmetry plane is also present in the figure to explain the effect of the profile of liquid-solid interface on the solidification parameters ( $G$ and $R$ ). In Fig. 9, the correlation between solidification direction (i.e. normal direction of the liquidus) and the slope of the liquidus contour ( $1498 \mathrm{~K}$ ) can be illustrated. A more horizontal slope of liquidus leads to a lower growth rate $R$, since the normal of surface is misaligned to the scanning direction. If the slope is nearly zero (horizontal) at the bottom of molten pool as shown in Fig. 9, the growth rate $R$ is nearly zero as well. On the other hand, the distance between solidus and liquidus (i.e. the width of the mushy region) can be used to discern qualitatively the value of temperature gradient $G$. A smaller distance between solidus and liquidus means a higher temperature gradient, such as the top and bottom of the molten pool in Fig. 9.

The spatial variability of $G$ and $R$ along the liquid-solid interface results in the variability in the solidification parameters, which impact the scale and morphology of microstructure. The cooling rate $G \times R$ and the morphology factor $G / R$ as the function of layer depth along the symmetry plane and the cross-section at the mid-length of different layers are present in Fig. 10(a) and (b). There are a local minimum and local maximum of both $G \times R$ and $G / R$ near the half of the molten pool at each layer. Because near the surface of molten pool, the profile of liquid-solid interface is significantly affected by the strong liquid metal flow, leading to the variation of $G$ and $R$ in this region. Higher cooling rate $G \times R$ is shown at the top of the molten pool (depth equals to zero) and the $G \times R$ is nearly zero at the bottom of molten pool (depth equals to about $1 \mathrm{~mm}$ ) as shown in Fig. 10(a). On the contrary, lower $G / R$ is found at the top and higher $G / R$ is shown at the bottom of the molten pool as shown in Fig. 10(b). For example, at the first layer, the $G \times R$ changes from $6000 \mathrm{~K} / \mathrm{s}$ (at the top of molten pool) to zero (at the bottom of molten pool), while the $G / R$ changes from $175 \mathrm{~K} \mathrm{~s} /$ $\mathrm{mm}^{2}$ (at the top) to $480 \mathrm{~K} \mathrm{~s} / \mathrm{mm}^{2}$ (at the bottom). These trends imply that the microstructure in the first track is prone to finer equiaxed dendrites at the top of the track and coarser planar front at the bottom of the track.

The influence of subsequent progress on the solidification parameters $(G \times R$ and $G / R)$ is also illustrated in Fig. 10. The $G \times R$ significantly declines with the increase of layer number. The maximum value of $G \times R$ changes from $6010 \mathrm{~K} / \mathrm{s}$ at the top of first layer to $4700 \mathrm{~K} / \mathrm{s}$ at the top of third layer to $3980 \mathrm{~K} / \mathrm{s}$ at the top of sixth layer, which implies that the scale of the grains is coarser at higher layers. However, there is no obviously change in $G / R$ as the layer number increases (i.e. $G$ and $R$ proportionally decrease), which means the morphology of microstructure may

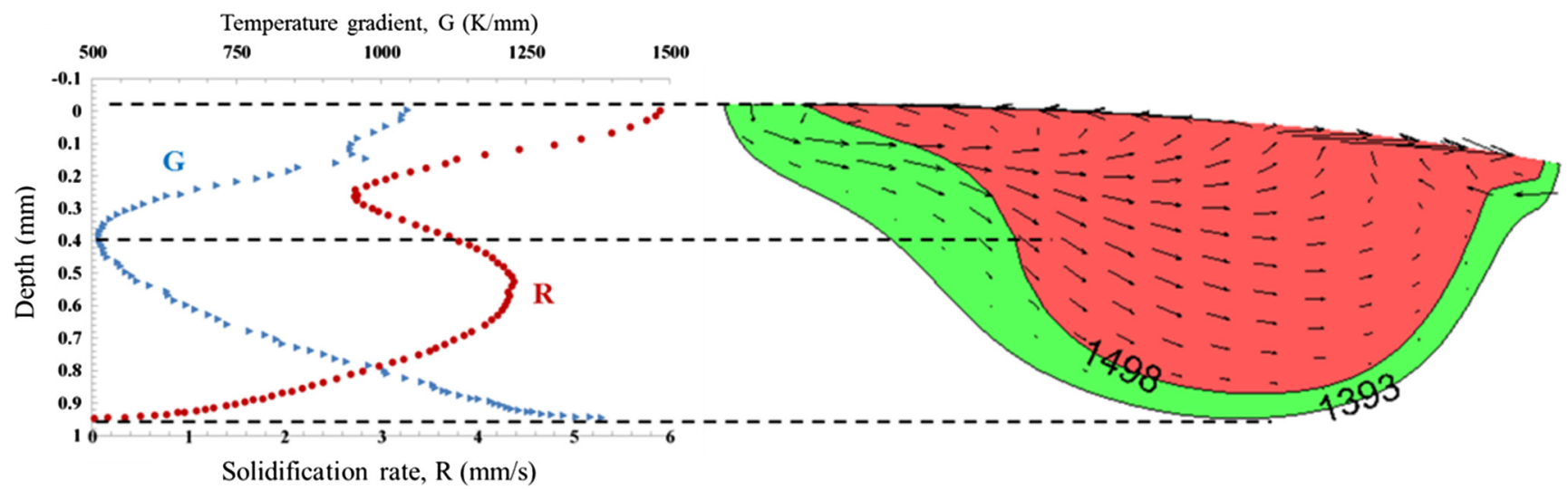

Fig. 9. The variation of $G$ and $R$ as the function of layer depth along the symmetry place. 

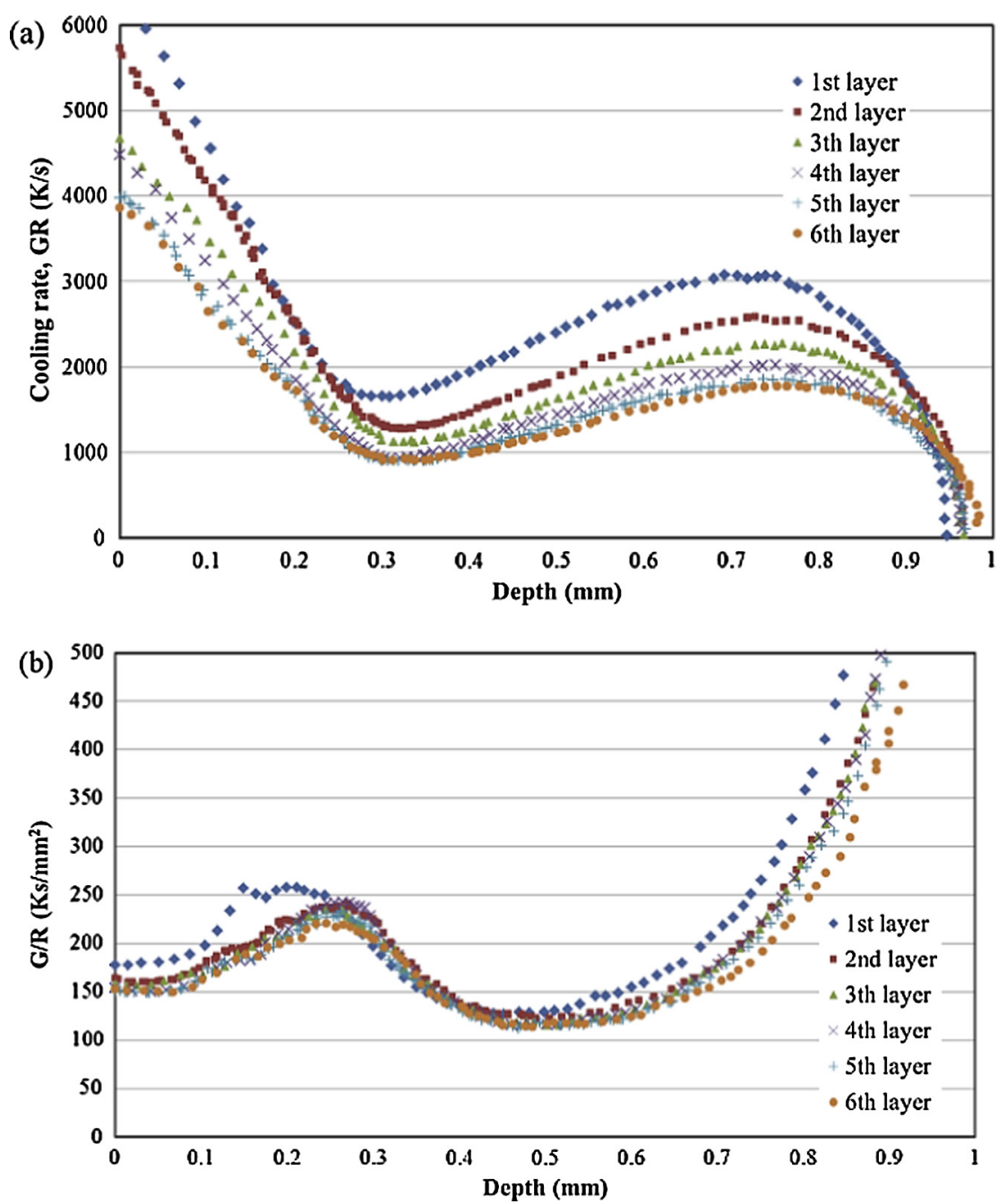

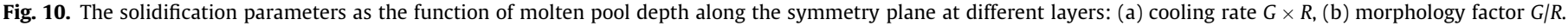

not remarkably change at different layer. In order to validate the simulation results, Fig. 11 shows the relevant experimental microstructure at the top region of cross-section in 1st, 3rd, and 6 th layer. The calculated solidification parameters $(G \times R$ and $G /$ $R$ ) and measured average primary dendrite arm spacing (PDAS) and secondary dendritic arm spacing (SDAS) in $\mu \mathrm{m}$ are also marked in the figure. The experimental results show that at the top of first layer, the microstructure is the finer columnar dendrites. The aver- age PDAS and SDAS are about $22 \mu \mathrm{m}$ and $1.9 \mu \mathrm{m}$, respectively. As the layer number increases, in the 3rd and 6th layer, the average PDAS increases to about $27 \mu \mathrm{m}$ and $31 \mu \mathrm{m}$, respectively, and the average SDAS also increases to about $2.5 \mu \mathrm{m}$ and $3.1 \mu \mathrm{m}$, respectively. However, the morphology of microstructure is still dominated by the columnar dendrites. The simulation predictions are strongly supported by the experimentally observed microstructure.
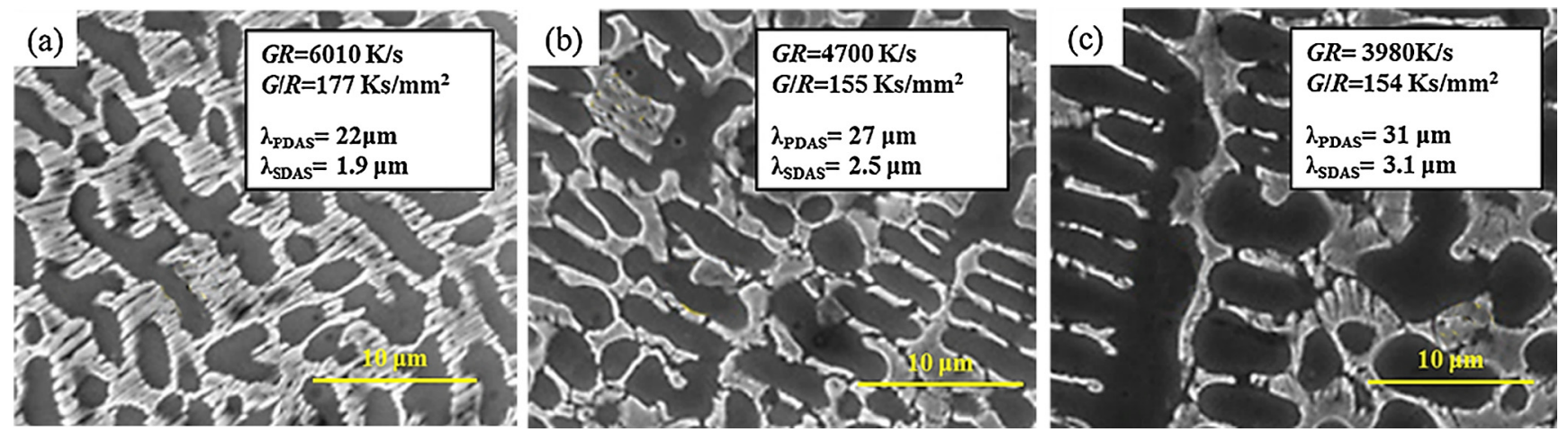

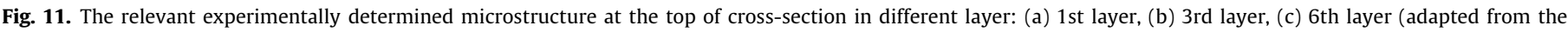
literature [35], with permission from Elsevier). 


\subsection{Mass transport}

\subsubsection{Solute transfer}

Besides the heat transfer, the mass transfer also significantly impacts the solidification behavior and mechanical properties of deposited layer [37]. Thus the mass transfer processes during the laser additive manufacturing, including solute transfer in the molten pool, macro/micro-segregation, and solute redistribution in micro-scale should be thoroughly understood. During laser additive manufacturing process, addition of dissimilar-metal powder results in the solutes redistribution within the molten pool. Consequently, the mass transport of components in the molten pool affects the final composition distribution and mechanical properties of part. The mass transfer in single-track additive manufacturing has been reported in published literatures [11]. Thus, this study mainly focuses on the mass transport in multi-layer additive manufacturing process.

Fig. 12(a)-(f) present the computed concentration profile of $\mathrm{Ni}$ at different times (i.e. different layers). The elemental $\mathrm{Ni}$ is indicated by weight fraction. The liquidus $(1498 \mathrm{~K})$ and solidus
( $1393 \mathrm{~K})$ are also shown by the black isotherms in the figure. Diffusion and convection are the main mass transfer mechanisms in the molten pool for laser additive manufacturing. These two mechanisms can be estimated by the dimensionless number $P e_{\mathrm{m}}$ as follow [32],

$P e_{m}=\frac{u L_{R}}{D}$

Based on the calculation, the $P e_{m}$ in the molten pool is on the order of $10^{4}$. The convection dominates the mass transport within the molten pool. Thus, at the each layer, the composition distribution in the molten pool quickly becomes uniform due to the strong Marangoni convection after a short premixing stage. However, multiple remelting processes during laser additive manufacturing lead to more complicated mass transport and composition profile. As shown in Fig. 12(b), the second layer deposits and remelts the top part of the first layer due to bidirectional scanning of laser beam. Because the $\mathrm{Ni}$-containing powders are continuously injected into the molten pool (The weight fraction of $\mathrm{Ni}$ in the powder is taken as $63 \mathrm{wt} \%$ ), the concentration of $\mathrm{Ni}$ in the molten pool
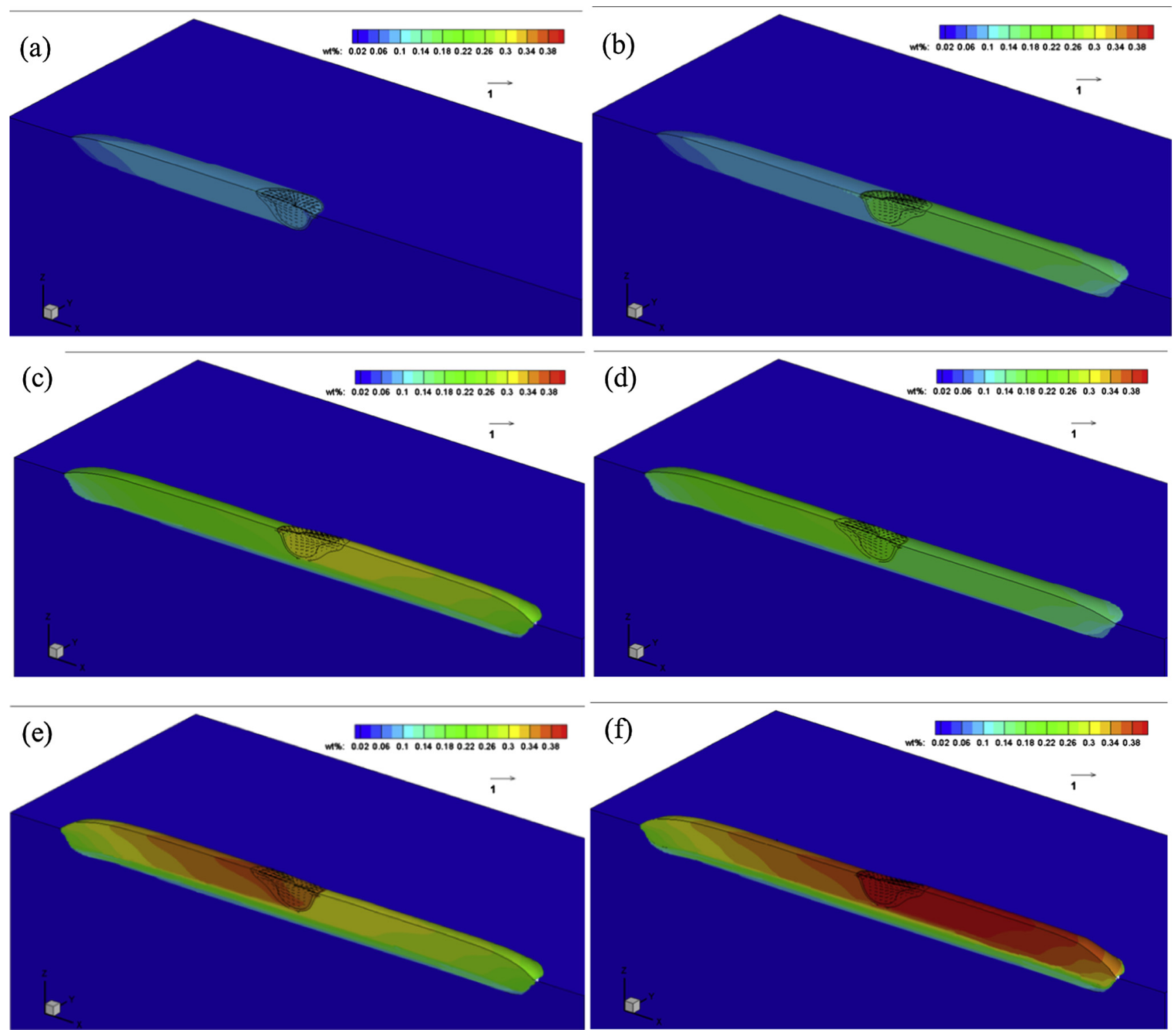

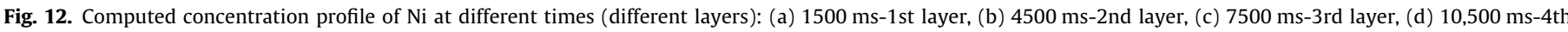
layer, (e) $13,500 \mathrm{~ms}-5$ th layer, and (f) $16,500 \mathrm{~ms}-6$ th layer 


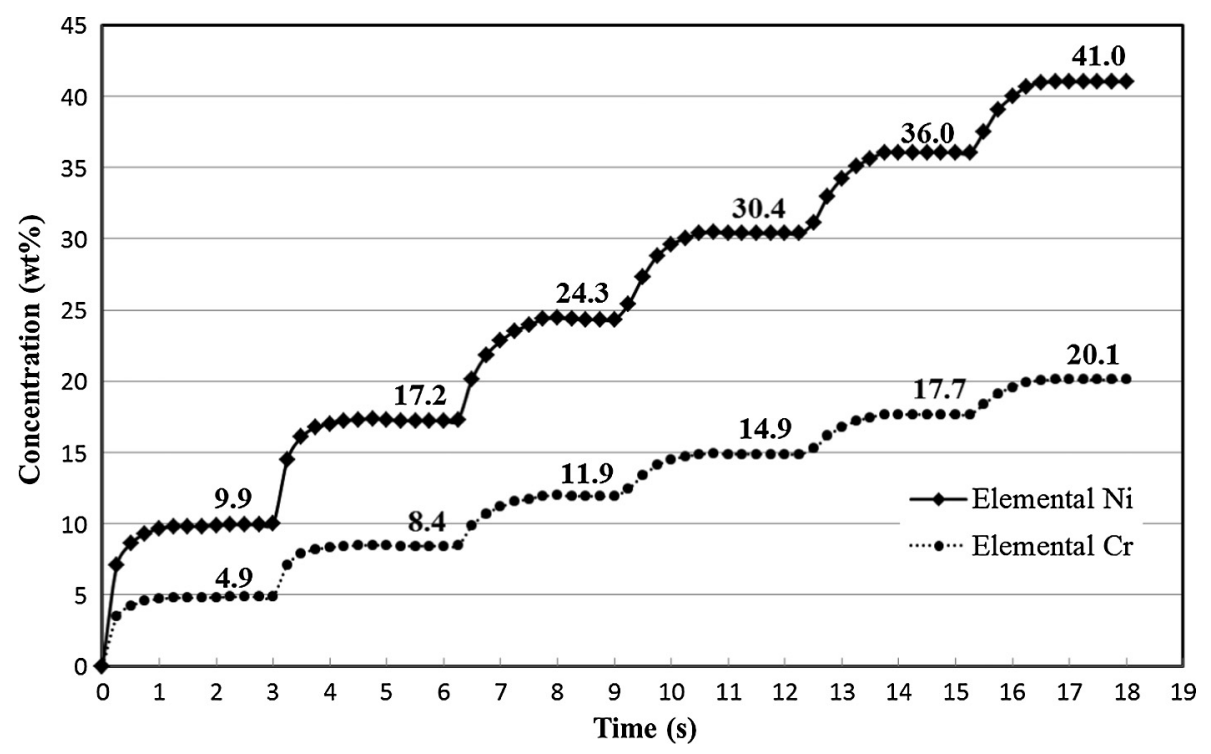

Fig. 13. Variation of the maximum concentration of elemental $\mathrm{Ni}$ and $\mathrm{Cr}$ in the domain as the function of time.

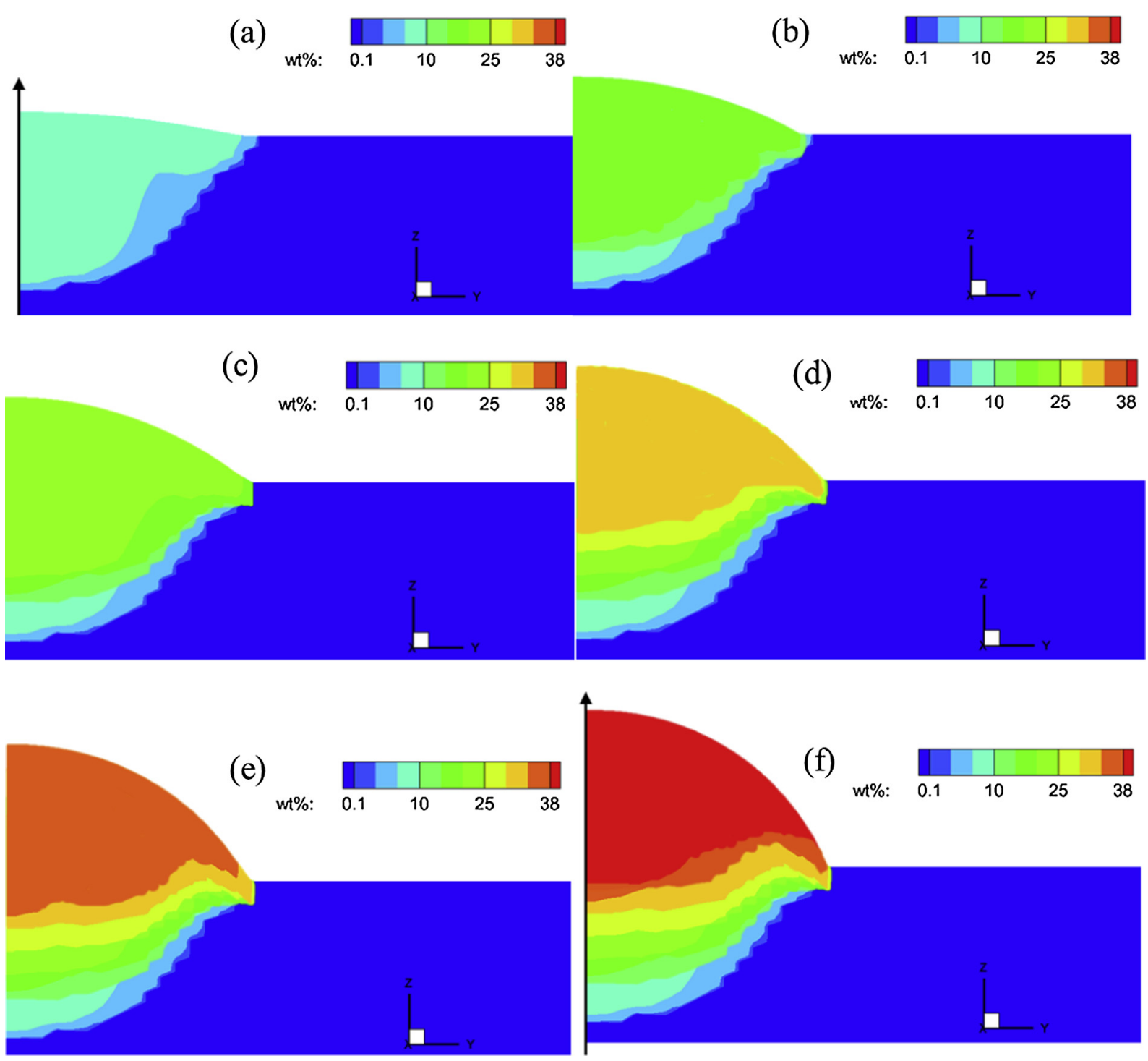

Fig. 14. Calculated composition profile of $\mathrm{Ni}$ in the cross-section for parts of different layers: (a) one layer, (b) two layers, (c) three layers, (d) four layers, (e) five layers, and (f) six layers. 
significantly increases at the second layer as shown in Fig. 12(b). As the layer number increases, the concentration of $\mathrm{Ni}$ in the molten pool increases, which leads to higher concentration of $\mathrm{Ni}$ at higher layer of part as shown in Fig. 12. It is noteworthy that since the subsequent layer cannot remelt the entire portion of previous layer, the bottom portion of the previous layer remains the previous concentration of $\mathrm{Ni}$, resulting in a stair-stepping concentration distribution at the bottom of part as shown in Fig. 12(b)-(f). A concentration transition zone from $10 \mathrm{wt} \%$ to $41 \mathrm{wt} \%$ exists at the bottom of the part as shown in Fig. 12(f).

The maximum concentration of elemental $\mathrm{Ni}$ and $\mathrm{Cr}$ in the domain as the function of time are shown in Fig. 13. The steadystate concentration of $\mathrm{Ni}$ and $\mathrm{Cr}$ in the molten pool of each layer is also marked in the figure. As shown in Fig. 13, the maximum concentration reaches a constant after a rapid increasing period in each layer. The time of premixing for each layer is about $900 \mathrm{~ms}$ in this study. The steady-state concentration of $\mathrm{Ni}$ for each layer is $9.9 \mathrm{wt} \%, 17.2 \mathrm{wt} \%, 24.3 \mathrm{wt} \%, 30.4 \mathrm{wt} \%, 36 \mathrm{wt} \%$, and $41 \mathrm{wt} \%$, respectively. The trend of concentration variation of elemental $\mathrm{Cr}$ is similar to that of elemental $\mathrm{Ni}$, because of the similar mass transfer mechanism of $\mathrm{Ni}$ and $\mathrm{Cr}$.

\subsubsection{Composition profile}

Fig. 14(a)-(f) presents the calculated composition profile of $\mathrm{Ni}$ in the cross-section for the parts of different layers. As shown in Fig. 14(a), the solute concentration in the molten pool is uniform except for the vicinity region of the fusion boundary. As the deposition proceeds, the height of layer increases as expected. Furthermore, the concentration of solute increases as well at the remelting region of the part due to the dissimilar-metal powder addition. As shown in Fig. 14(b), an obvious stair-stepping concentration distribution is observed at the bottom of the part. Because the remelting only occurs at the top part of previous layer, the concentration of the bottom of previous layer remains. As the deposition proceeds, the non-uniform concentration distribution at the bottom can be observed. In this composition transition zone, the concentration of $\mathrm{Ni}$ increases from $10 \mathrm{wt} \%$, the concentration of molten pool at the first layer, to $41 \mathrm{wt} \%$, the concentration at the sixth layer.
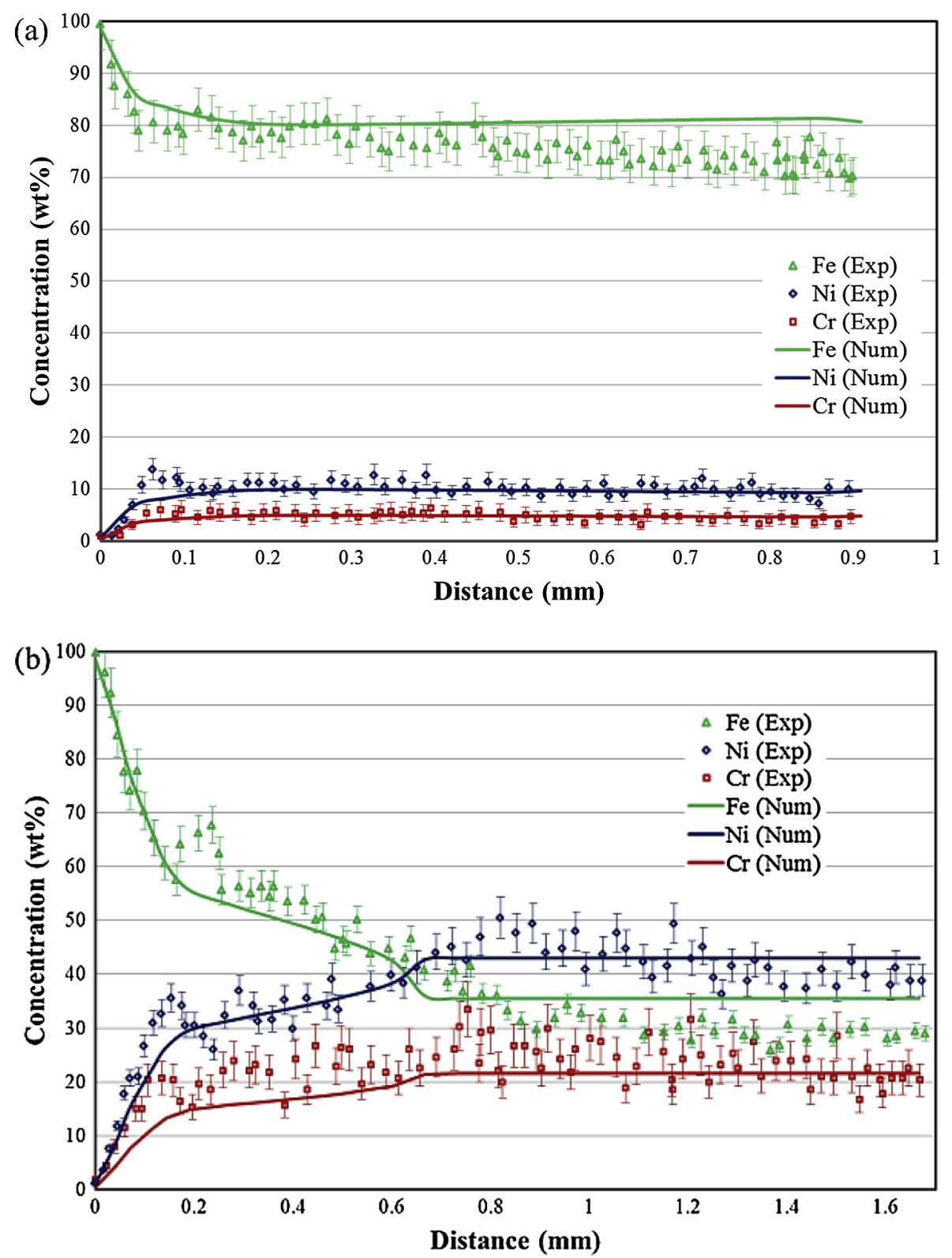

Fig. 15. Calculated and experimental weight fraction of $\mathrm{Fe}, \mathrm{Ni}$, and $\mathrm{Cr}$ in the cross-section of parts: (a) one layer, (f) six layers. 
In order to validate the simulation results, Fig. 15(a) and (b) show the computed and experimental weight fraction of $\mathrm{Fe}, \mathrm{Ni}$, and $\mathrm{Cr}$ in the cross-section for one layer and six layers of deposited structure. Energy Dispersive Spectrometer (EDS) was used to measure the composition distributions of samples [35]. The scanning track of EDS is present in Fig. 14(a) and (f). As shown in Fig. 15, the experimental measurements well agree with the calculated predictions of composition distribution. There are few deviations between calculated and experimental results due to the simplicity of present model. The thermoproperties of materials are temperature-independent, except the laser energy absorptance. The Gaussian distribution of laser beam and powder flow also may result in some deviations. As seen in Fig. 15, the computed composition of $\mathrm{Fe}$ is higher than the experimental composition. Because some kinds of elements in the powder and substrate, such as $\mathrm{Al}(3.4 \mathrm{wt} \%), \mathrm{Co}(2.6 \mathrm{wt} \%)$, and $\mathrm{C}(3.6 \mathrm{wt} \%)$, are neglected in this calculation to simplify. Even so, the relative error is less than $15 \%$ between calculated and experimental results, which validates the proposed heat and mass transfer model in this work.

The proposed numerical model is beneficial to the understanding of the transport phenomena and designing optimized process parameters in one-step fabrication of complex parts and functionally graded materials by using additive manufacturing technology. It is reasonable to expect that this model will be conveniently developed to take into account more detailed solidification behavior and solute segregation during advanced additive manufacturing processes. The spatial-temporal variant of solidification parameters and dimensionless number could be further investigated in the future.

\section{Conclusions}

The multiple thermal cycles, and the scale and morphology of microstructure are examined based on the transient temperature distribution. Multi-layer solute transport and solidified composition profile are present. The calculated molten pool dimensions, microstructure and macroscopic composition profile agree well with the experimental determined results. Some conclusions can be drawn as listed:

(1) The Peclet number for heat transfer is more than $10^{2}$ after the formation of molten pool in laser additive manufacturing. The strong Marangoni convection dominates the heat transport in the molten pool. The results of numerical simulations present that neglecting the liquid metal flow leads to overestimated temperature field as well as the solidification parameters. More realistically and reliable thermal behavior can be obtained by the present heat transfer and fluid flow model

(2) The calculated cooling rate $G \times R$ declines progressively as the subsequent layers deposit. The maximum cooling rate GR declines from $6000 \mathrm{~K} / \mathrm{s}$ at the top of the first layer to $3980 \mathrm{~K} / \mathrm{s}$ at the top of the sixth layer, which result in the coarser solidified grains at higher layers. The independent observation of microstructure strongly supports the simulation results. At the top region of the $1 \mathrm{st}, 3 \mathrm{rd}$, and 6 th layer, the average primary dendrite arm spacing is about $22 \mu \mathrm{m}$, $27 \mu \mathrm{m}$ and $31 \mu \mathrm{m}$, respectively, and the average secondary dendrite arm spacing is about $1.9 \mu \mathrm{m}, 2.5 \mu \mathrm{m}$ and $3.1 \mu \mathrm{m}$, respectively. On the other hand, there is no obviously change in the computed $G / R$ as the layer number increases while the columnar dendrites are observed at different layers of experimental samples.

(3) The Peclet number for mass transfer in the molten pool is on the order of $10^{4}$. The convection dominates the mass trans- port within the molten pool. At each layer, the composition distribution in the molten pool quickly becomes uniform due to the strong Marangoni convection after a short premixing stage (about $900 \mathrm{~ms}$ in this study). Due to continuous powder addition and multiple remelting, the steadystate concentration of $\mathrm{Ni}$ for each layer remarkably increases. An obvious non-uniform concentration distribution is observed at the bottom of the solidified part. In this composition transition zone, the concentration of $\mathrm{Ni}$ increases from $9.9 \mathrm{wt} \%$, the concentration of molten pool at first layer, to $41 \mathrm{wt} \%$, the concentration at sixth layer in this case.

\section{Acknowledgment}

This work was supported by the National Natural Science Foundation of China under grant No. 11272316, 11272317, and 11502269. This work was also supported by the Natural Science Foundation of Jiangsu Province (Grant No. BK20160258).

\section{References}

[1] W. Yan, W. Ge, J. Smith, et al., Multi-scale modeling of electron beam melting of functionally graded materials, Acta Mater. (2016) 403-412.

[2] J. Smith, W. Xiong, W. Yan, et al., Linking process, structure, property, and performance for metal-based additive manufacturing: computational approaches with experimental support, Comput. Mech. 57 (2016) 583-610.

[3] S. Wen, Y.C. Shin, Modeling of transport phenomena during the coaxial laser direct deposition process, J. Appl. Phys. 108 (2010) 044908.

[4] Y.S. Lee, M. Nordin, S.S. Babu, et al., Influence of fluid convection on weld pool formation in laser cladding, Weld. J. 93 (2014) 292S-300S.

[5] H.L. Wei, J. Mazumder, T. Debroy, et al., Evolution of solidification texture during additive manufacturing, Sci. Rep. 5 (2015) 16446.

[6] X. He, L. Song, G. Yu, et al., Solute transport and composition profile during direct metal deposition with coaxial powder injection, Appl. Surf. Sci. 258 (2011) 898-907.

[7] T. Mukherjee, J.S. Zuback, A. De, et al., Printability of alloys for additive manufacturing, Sci. Rep. 6 (2016) 1-6.

[8] H. Qi, J. Mazumder, H. Ki, et al., Numerical simulation of heat transfer and fluid flow in coaxial laser cladding process for direct metal deposition, J. Appl. Phys. 100 (2006) 024903-24911.

[9] X. He, J. Mazumder, Transport phenomena during direct metal deposition, J. Appl. Phys. 101 (2007) 053113-53119.

[10] A. Kumar, S. Roy, Effect of three-dimensional molten pool convection on process characteristics during laser cladding, Comput. Mater. Sci. 46 (2009) 495-506.

[11] Z. Gan, G. Yu, X. He, et al., Numerical simulation of thermal behavior and multicomponent mass transfer in direct laser deposition of Co-base alloy on steel, Int. J. Heat Mass Trans. 104 (2017) 28-38.

[12] S.A. Khairallah, A.T. Anderson, A.M. Rubenchik, et al., Laser powder-bed fusion additive manufacturing: physics of complex melt flow and formation mechanisms of pores, spatter and denudation zones, Acta Mater. 108 (2015) 36-45.

[13] G. Bi, C. Sun, H. Chen, et al., Microstructure and tensile properties of superalloy IN100 fabricated by micro-laser aided additive manufacturing, Mater. Des. 60 (2014) 401-408.

[14] R.S. Lakhkar, Y.C. Shin, M.J.M. Krane, Predictive modeling of multi-track laser hardening of AISI 4140 steel, Mater. Sci. Eng. A-Struct. 480 (2008) 209-217.

[15] V.D. Manvatkar, A.A. Gokhale, G.J. Reddy, et al., Estimation of molten pool dimensions, thermal cycle, and hardness distribution in the laser-engineered net shaping process of austenitic stainless steel, Metall. Mater. Trans. A 42 (2011) 4080-4087.

[16] N. Raghavan, R. Dehoff, S. Pannala, et al., Numerical modeling of heat-transfer and the influence of process parameters on tailoring the grain morphology of IN718 in electron beam additive manufacturing, Acta Mater. 112 (2016) 303314.

[17] Y. Hu, X. He, Y. Gang, et al., Heat and mass transfer in laser dissimilar welding of stainless steel and nickel, Appl. Surf. Sci. 258 (2012) 5914-5922.

[18] S. Morville, M. Carin, P. Peyre, et al., 2D longitudinal modeling of heat transfer and fluid flow during multilayered direct laser metal deposition process, J. Laser Appl. 24 (2012), 032008-1-9.

[19] S. Wen, Y.C. Shin, Comprehensive predictive modeling and parametric analysis of multitrack direct laser deposition processes, J. Laser Appl. 23 (2011) 807819.

[20] V. Manvatkar, A. De, T. Debroy, et al., Heat transfer and material flow during laser assisted multi-layer additive manufacturing, J. Appl. Phys. 116 (2014) 124905-124908. 
[21] C. Guo, W. Ge, F. Lin, Dual-material electron beam selective melting: hardware development and validation studies, Ocean Eng. 1 (2015) 124-130.

[22] B. Norhafzan, S.N. Aqida, E. Chikarakara, et al., Surface modification of AISI H13 tool steel by laser cladding with NiTi powder, Appl. Phys. A 122 (2016) 1-6.

[23] W. Gao, S. Zhao, Y. Wang, et al., Numerical simulation of thermal field and Febased coating doped Ti, Int. J. Heat Mass Trans. 92 (2016) 83-90.

[24] J. Schneidewind, M. Sips, D.A. Keim, Probing liquation cracking and solidification through modeling of momentum, heat, and solute transport during welding of aluminum alloys, J. Appl. Phys. 97 (2005) 4912-094912.

[25] S. Asai, I. Muchi, Theoretical analysis and model experiments on the formation mechanism of channel-type segregation, Trans. Iron Steel Inst. Jpn. 18 (1978) 90-98.

[26] A. Kar, J. Mazumder, Model for nonequilibrium partitioning during rapid solidification of binary concentrated solutions, Acta Metall. Mater. 40 (1992) 1873-1881.

[27] C.H. Kim, W. Zhang, T. Debroy, Modeling of temperature field and solidified surface profile during gas-metal arc fillet welding, J. Appl. Phys. 94 (2003) 2667-2679.

[28] W. Zhang, C.H. Kim, T. Debroy, Heat and fluid flow in complex joints during gas metal arc welding-Part I: Numerical model of fillet welding, J. Appl. Phys. 95 (2004) 5210-5219.
[29] J. Xie, A. Kar, J.A. Rothenflue, et al., Temperature-dependent absorptivity an cutting capability of $\mathrm{CO}_{2}$, Nd:YAG and chemical oxygen-iodine lasers, J. Laser Appl. 9 (1997) 77-85.

30] G. Pottlacher, H. Hosaeus, E. Kaschnitz, et al., Thermophysical properties of solid and liquid Inconel 718 alloy, Scand. J. Metall. 31 (2002) 161-168.

[31] H. Gedda, A. Kaplan, J. Powell, Melt-solid interactions in laser cladding and laser casting, Metall. Mater. Trans. B 36 (2005) 683-689.

[32] Q.M. Tan, Dimensional Analysis, Springer, Berlin Heidelberg, 2011.

[33] C.S. Wu, J.W. Chen, Y.M. Zhang, et al., Numerical analysis of both front- and back-side deformation of fully-penetrated GTAW weld pool surfaces, Comput. Mater. Sci. 39 (2007) 635-642.

34] E.A. Brandes, Smithells Metals Reference Book, Butterworths, 1983.

[35] H. Liu, J. Hao, Z. Han, et al., Microstructural evolution and bonding characteristic in multi-layer laser cladding of $\mathrm{NiCoCr}$ alloy on compacted graphite cast iron, J. Mater. Process. Tech. 232 (2016) 153-164.

[36] J.C. Lippold, Welding Metallurgy and Weldability, John Wiley \& Sons, 2014

37] M.M. Kirka, K.A. Unocic, N. Raghavan, et al., Microstructure development in electron beam-melted Inconel 718 and associated tensile properties, JOM 68 (2016) 1-9. 